\title{
Identification, characterization and functional analysis of grape (Vitis vinifera L.) mitochondrial transcription termination factor (mTERF) genes in responding to biotic stress and exogenous phytohormone
}

Xiangjing Yin ${ }^{1 \dagger}$, Yu Gao ${ }^{1+}$, Shiren Song ${ }^{1}$, Danial Hassani ${ }^{2}$ and Jiang Lu ${ }^{1 *}$

\begin{abstract}
Background: Mitochondrial transcription termination factor (mTERF) is a large gene family which plays a significant role during plant growth under various environmental stresses. However, knowledge of mTERF genes in grapevine (Vitis L.) is limited.

Results: In this research, a comprehensive analysis of grape mTERF (VVMTERF) genes, including chromosome locations, phylogeny, protein motifs, gene structures, gene duplications, synteny analysis and expression profiles, was conducted. As a result, a total of 25 mTERF genes were identified from the grape genome, which are distributed on 13 chromosomes with diverse densities and segmental duplication events. The grape mTERF gene family is classified into nine clades based on phylogenetic analysis and structural characteristics. These VVmTERF genes showed differential expression patterns in response to multiple phytohormone treatments and biotic stresses, including treatments with abscisic acid and methyl jasmonate, and inoculation of Plasmopara viticola and Erysiphe necator.
\end{abstract}

Conclusions: These research findings, as the first of its kind in grapevine, will provide useful information for future development of new stress tolerant grape cultivars through genetic manipulation of VVmTERF genes.

Keywords: Bioinformatics analysis, Expression profile analysis, Grapevine (V. vinifera L.), mTERF family

\section{Background}

In eukaryotes, genetic information is not only stored in the nucleus, but also in organelle genomes such as mitochondria and chloroplasts. However, these organelles' gene pool has dramatically reduced during their evolution, which is due to the loss of their genes, and continuous transfer of organelle-nuclear genes [1-3]. In living

\footnotetext{
* Correspondence: vitislab@sjtu.edu.cn

${ }^{+}$Xiangjing Yin and Yu Gao contributed equally to this work.

${ }^{1}$ Center for Viticulture and Enology, School of Agriculture and Biology, Shanghai Jiao Tong University, Shanghai 200240, China

Full list of author information is available at the end of the article
}

organisms, the organelle gene expression system largely depends on nuclear-coding proteins, which include RNA polymerase, sigma factor, as well as specific RNA maturation factors [4-8]. Meanwhile, some organelle protein families including, PPRs, HAT, OPRs and mTERFs which have similar modular structures consisting of repetitive helical motifs also play an important role in their gene expression mechanism $[4,9]$.

Mitochondrial transcription termination factor (mTERF) genes comprise a large family which plays an essential role in the regulation of mitochondrial gene

(c) The Author(s). 2021 Open Access This article is licensed under a Creative Commons Attribution 4.0 International License, which permits use, sharing, adaptation, distribution and reproduction in any medium or format, as long as you give appropriate credit to the original author(s) and the source, provide a link to the Creative Commons licence, and indicate if changes were made. The images or other third party material in this article are included in the article's Creative Commons licence, unless indicated otherwise in a credit line to the material. If material is not included in the article's Creative Commons licence and your intended use is not permitted by statutory regulation or exceeds the permitted use, you will need to obtain permission directly from the copyright holder. To view a copy of this licence, visit http://creativecommons.org/licenses/by/4.0/ The Creative Commons Public Domain Dedication waiver (http://creativecommons.org/publicdomain/zero/1.0/) applies to the data made available in this article, unless otherwise stated in a credit line to the data. 
transcription [10]. MTERF proteins possess a unique repetition of 30 amino acids residue, which enables them to recognize and bind to specific sites on mitochondrial genome known as typical mTERF motif [11]. In human for instance, mTERFs comprises a proline at position 8 , 11, 18 and 25. Therefore, the motif is conserved for leucine or hydrophobic amino acids, indicating that there are at least three leucine motifs in the mTERFs [12]. Former research indicated that mTERF proteins could have multiple biological functions of intracellular regulation. For instance, human mTERF1, with 342 amino acids in length, can bind to 28 nucleotide sequences downstream of the 3'end of 16SrRNA, leading to the termination of mitochondrial gene transcription [13, 14]. The mTERF1 protein possess regulatory function for transcriptional initiation of mitochondrial rDNA and mitochondrial DNA replication [15]. In addition, mTERF2 protein showed a significant downregulation of mitochondrial transcription level in vitro, suggesting that mTERF2 protein may affect mitochondrial transcription by binding with regulatory activators of mtDNA transcription initiation [16].

In recent years, plant mTERF genes and their roles in mitochondrial gene expression regulation have received a good deal of attention [17]. Bioinformatic analysis shows that these mTERF genes are a large and complex family existing in metazoans and plants [18]. There are at least identified 35 mTERFs in Arabidopsis thaliana, mainly located in mitochondria or chloroplasts, participating in abiotic stresses $[19,20]$. For instance, the seed germination rate of mterf1 (soldat 10) mutant was considerably lower than wild type under the same condition [21]. Over expression of the AtmTERF5 (MDA1) gene affects the germination rate of transgenic lines under simulated drought stress as higher germination rate was observed under mannitol treatment [22]. Besides, $A$. thaliana mterf9 mutant was insensitive to ABA treatment. Under the treatment of $\mathrm{NaCl}$ and $\mathrm{ABA}$, the root growth retardation of mTERF9 mutants displayed the phenotype of short root and lighter fresh weight compared to the wild type [23]. Furthermore, previous studies in maize showed that ZmmTERF4 protein can coimmunoprecipitated with multiple chloroplast introns leading to the disruption of splicing in $\mathrm{Zm}$-mterf4 mutants, indicating its key role in meditating the communication between organelle and the nucleus [24]. The evidence expands the functional knowledge of the mTERF family.

As a large economic worth fruit crop [25], grapevine is an important candidate for identifying stress resistance genes to leading to better grape quality. At present, the basic structure and preliminary functions of mTERF family proteins have been continuously explored, but their detailed functions and regulation mechanisms under different stresses still remain unknown. This study introduces the members of the grape mTERF gene family $(V v m T E R F)$ and determine their potentiality in stress resistance, aiming to afford an essential information of the grape mTERF gene family and providing a resource for functional research in grape biology study.

\section{Results}

\section{Identification of $M T E R F$ genes in grape genome}

MTERF genes in the grape genome were identified by BLASTP with HMMER 3.0 [26] searching key domain mTERF PFAM file (PF02636) and previous reports [20, 27]. A total of 25 grape mTERF genes were identified, which were named as VvmTERF1-VvmTERF25 according to sequence of their chromosomal locations (Table 1). A high conserved mTERF domain was found in all the VvmTERF proteins.

\section{Phylogenetic analysis and classification of grape $m$ TERF genes}

In order to evaluate the evolutionary relationship of VvmTERF gene family, a total of 91 mTERF genes from Arabidopsis (35), maize (31) and grape (25) genomes were collected for a phylogenetic tree construction using MEGA5.0 software (Fig. 1 and Figure S1). Detailed sequence information of Arabidopsis and maize mTERF genes were obtained from a previous study [28]. The tree topology result demonstrated that nine groups (Clade I-IX) were classified according to homologous genes of maize and Arabidopsis. Of the 25 VvmTERF genes, Clade VII contained 7 genes, the most among all the clades, while other clades had 1 to 5 members, respectively. One grape mTERF gene, VvmTERF24, belonged to Clade I where 2 members were identified in Arabidopsis and in maize $[20,28]$. It is worth noting that the well functional characterized mTERF genes from Arabidopsis, such as SOLDAT10 (AtmTERF1, AT2G03050), BSM/RUG2 (AtmTERF4, AT4G02990), and SHOT1 (AtmTERF18, AT3G60400) were distributed in group II, IV and VI, respectively. Meanwhile, a certain of grape mTERF genes belong to these groups, indicated their close evolutionary relationships with Arabidopsis mTERF genes from the same group.

\section{Exon-intron structure analysis of VvmTERF genes}

Structure analysis on the exon and intron boundaries of the VVmTERF genes will provide important clues as they played significant roles in evolution of various gene families. The number of exons per grape mTERF gene ranged from 1 to 22 (Fig. 2). Among them, VvmTERF20 had the highest number of exons of 22, followed by VvmTERF14 (10), VvmTERF16 (7), VvmTERF18 (6), VvmTERF9 (6), VvmTERF24 (6) and VvmTERF4 (6), while VvmTERF3, VvmTERF8, VvmTERF11-13 and 
Table 1 The grape mTERF gene family

\begin{tabular}{|c|c|c|c|c|c|c|c|}
\hline Protein name & Gene locus & Chromosome location & Strand & CDS (bp) & Protein (aa) & mTERF domain location (aa) & E-value \\
\hline VvmTERF1 & GSVIVT01010499001 & chr1: $21096155 \ldots 21107668$ & - & 822 & 273 & $99-237$ & $5.32 \mathrm{e}-24$ \\
\hline VvmTERF2 & GSVIVT01023845001 & chr3: $3030639 . .3032099$ & - & 1065 & 354 & $72-344$ & $1.16 \mathrm{E}-54$ \\
\hline VvmTERF3 & GSVIVT01031956001 & chr3: 5686087...5687004 & - & 831 & 276 & $26-271$ & $1.39 \mathrm{e}-31$ \\
\hline VvmTERF4 & GSVIVT01031970001 & chr3: 5802834...5807050 & - & 1581 & 526 & $149-455$ & $2.34 \mathrm{E}-70$ \\
\hline \multirow[t]{2}{*}{ VvmTERF5 } & GSVIVT01017772001 & chr5: $3341975 \ldots . .3348425$ & - & 1284 & 427 & $49-165$ & $5.59 \mathrm{E}-17$ \\
\hline & & & & & & $213-358$ & $8.20 \mathrm{E}-05$ \\
\hline VvmTERF6 & GSVIVT01011061001 & chr7: $1887643 \ldots 1890890$ & + & 1596 & 531 & $55-490$ & $0.00 \mathrm{E}+00$ \\
\hline VvmTERF7 & GSVIVT01010970001 & chr7: $2517645 \ldots 2525482$ & + & 1227 & 408 & $84-357$ & $1.88 \mathrm{E}-33$ \\
\hline VvmTERF8 & GSVIVT01028380001 & chr7: 6844159...6845397 & + & 1239 & 412 & $97-371$ & $7.82 \mathrm{E}-41$ \\
\hline \multirow[t]{2}{*}{ VvmTERF9 } & GSVIVT01028382001 & chr7: $6850176 \ldots 6869742$ & + & 2367 & 788 & $120-339$ & $1.64 \mathrm{E}-30$ \\
\hline & & & & & & 409-738 & $5.17 \mathrm{E}-41$ \\
\hline \multirow[t]{2}{*}{ VvmTERF10 } & GSVIVT01028383001 & chr7: $6873625 \ldots 6888273$ & + & 2658 & 885 & $107-381$ & $4.50 \mathrm{E}-23$ \\
\hline & & & & & & $488-803$ & $2.62 \mathrm{E}-35$ \\
\hline VvmTERF11 & GSVIVT01028384001 & chr7: $6891622 \ldots 6892722$ & + & 1101 & 366 & $61-315$ & $1.29 \mathrm{E}-27$ \\
\hline VvmTERF12 & GSVIVT01022213001 & chr7: 17541013...17544022 & + & 1110 & 369 & $66-341$ & $6.11 \mathrm{E}-32$ \\
\hline VvmTERF13 & GSVIVT01033517001 & chr8: 20068603...20072280 & - & 1770 & 589 & $280-564$ & $6.81 \mathrm{E}-16$ \\
\hline VvmTERF14 & GSVIVT01029533001 & chr9: $21885971 \ldots 21897453$ & - & 2427 & 808 & $267-574$ & $6.49 \mathrm{E}-130$ \\
\hline VvmTERF15 & GSVIVT01021544001 & chr10: $6867305 \ldots 6869519$ & + & 738 & 245 & $139-227$ & $9.50 \mathrm{E}-20$ \\
\hline VvmTERF16 & GSVIVT01026275001 & chr10: $15271383 \ldots 15274580$ & - & 1692 & 563 & $254-520$ & $1.91 \mathrm{E}-10$ \\
\hline VvmTERF17 & GSVIVT01015207001 & chr11: 1833849...1837293 & - & 1662 & 553 & $17-338$ & $0.00 \mathrm{E}+00$ \\
\hline VvmTERF18 & GSVIVT01012810001 & chr11: $5607921 \ldots .5618868$ & & 2160 & 719 & $486-637$ & $1.50 \mathrm{E}-12$ \\
\hline VvmTERF19 & GSVIVT01001819001 & chr14: 26071265 ...26073597 & + & 1395 & 464 & $192-449$ & $4.80 \mathrm{E}-49$ \\
\hline VvmTERF20 & GSVIVT01038641001 & chr16: $21269851 \ldots 21283495$ & - & 5655 & 1884 & $196-492$ & $4.90 \mathrm{E}-32$ \\
\hline VvmTERF21 & GSVIVT01008120001 & chr17: $5628041 \ldots 5629396$ & - & 1356 & 451 & $84-278$ & $4.88 \mathrm{E}-10$ \\
\hline VvmTERF22 & GSVIVT01009012001 & chr18: 4269303...4275210 & - & 1278 & 425 & $86-353$ & $2.86 \mathrm{E}-26$ \\
\hline VvmTERF23 & GSVIVT01034475001 & chr18: 20728900...20735286 & - & 639 & 212 & 125-196 & $1.86 \mathrm{E}-08$ \\
\hline VvmTERF24 & GSVIVT01037780001 & chr19: 7803504...7814106 & + & 1443 & 480 & $195-470$ & $1.09 \mathrm{E}-40$ \\
\hline VvmTERF25 & GSVIVT01036787001 & chr19: 22546264...22547496 & + & 1233 & 410 & $94-368$ & $3.68 \mathrm{E}-45$ \\
\hline
\end{tabular}

VvmTERF21 had only one exon each. These results indicated that during the long evolution of VvmTERF gene family, both exon loss and gain have occurred, which might lead to diversified function among the other closely related mTERF genes. In clade IV, for instance, the number of exons was quite large, ranging from three to ten, while the genes in clade I and IX had a relatively smaller number, ranging from one to six exons. It is interesting that VvmTERF7, 8, 11 and 12 demonstrated similar exon/intron structures and came from the same clade while most VvmTERF genes showed distinct structures. This difference in exon/intron patterns might be resulted from a series of gene replication events.

\section{Conserved motifs and subcellular localization analysis of VVITERF}

Searching for putative conserved motifs in grape mTERF proteins analysis was conducted via Pfam [29] and
SMART [30] databases. In order to predict the potential motifs in the putative grape mTERF gene family gene sequences, the MEME (Multiple Em for Motif Elicitation) program [31] was used and 15 mTERF motifs in grape were identified and clustered (Fig. 2 and Table 2) using the ClustalW 2.0 program [32]. Among all, class VII sequences had more than 10 mTERF motifs, and clade IX mTERF sequences showed 5-8 mTERF motifs. Identified in human mTERF proteins previously [12], conversed mTERF motifs containing repeats of leucine zipper-like heptad $\mathrm{X}_{3} \mathrm{LX}_{3}$ structure was also found in grape mTERF motifs (Table 2), suggesting that fundamental structures and functions of mTERF proteins in Vitis might be similar to human mTERF proteins.

Aiming to find predicted motifs shared among related proteins within the grape mTERF gene family, the MEME database program [31] was performed. As shown in Fig. 2, a total of 15 motifs were discovered in these 25 


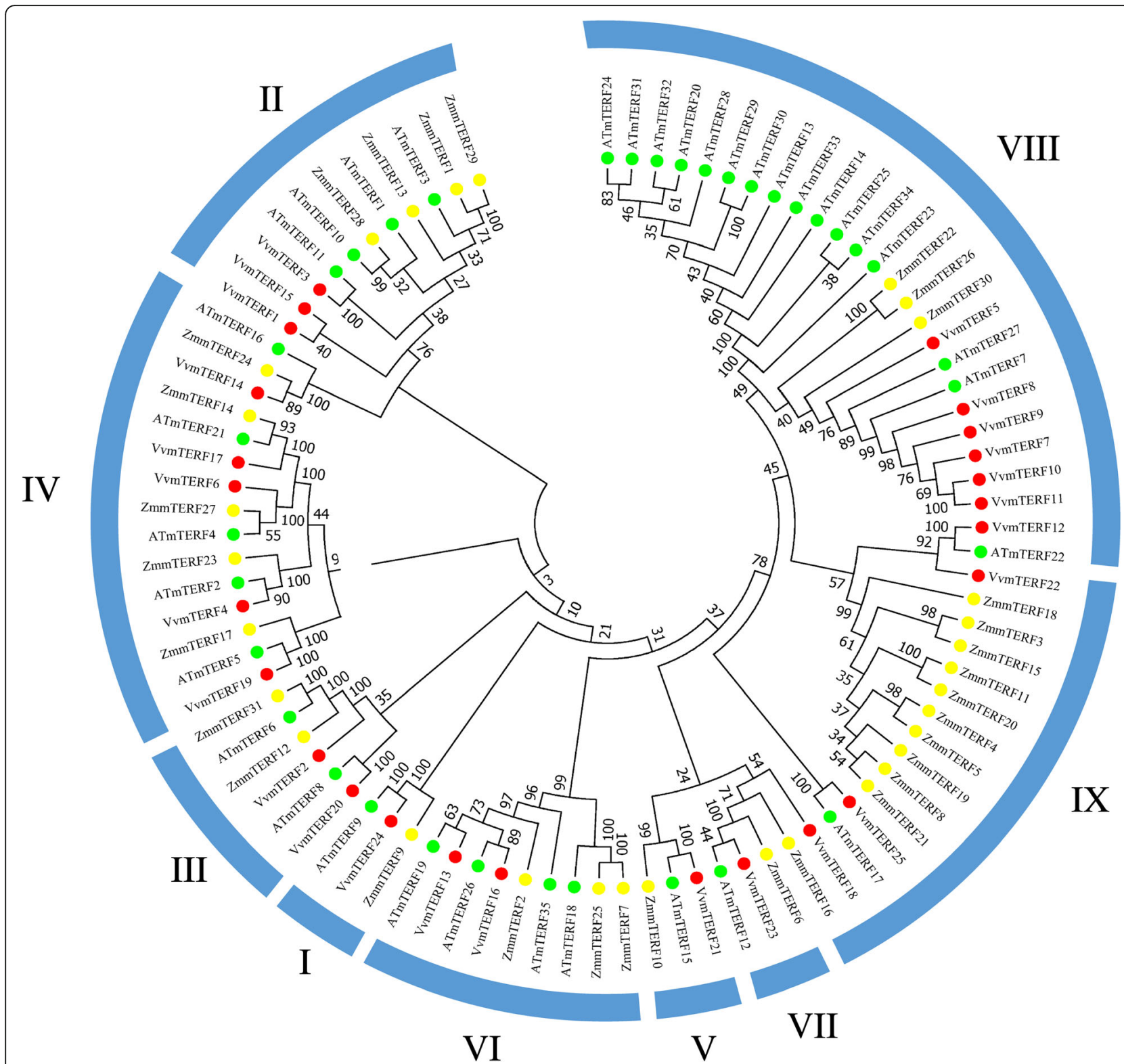

Fig. 1 Phylogenetic analysis among the grape, Arabidopsis and maize mTERF proteins. The unrooted tree was constructed using MEGA5.0 software by Neighbor-joining method. The numbers represent the bootstrap values (\%) for 1000 bootstrap replicates and only bootstrap values > $60 \%$ are shown. Nine groups designated I-IX are shown outside. Three dot colors mean different species. Yellow, green and red represent maize, Arabidopsis and grape, respectively

proteins. Among them, motifs 2 and 8 were found in most grape mTERF proteins. Motif sequences comparison with PFAM mTERF domain alignment revealed that motifs 1,4 and 5 partly covered the PFAM mTERF domain (PF02536), and motif 5 belonged to specific organelle-targeting mTERF proteins, such as the group IV grape mTERF proteins (Fig. 2). It is highly probabe that group-specific motifs lead to characteristic functions in various life activities.

In plants, the subcellular localization of a protein is closely related to its biological function. Table 3 indicates the predicted cellular location of VvmTERF proteins for future functional research. Based on protein sequence, subcellular localization prediction demonstrated that there are 12 VvmTERFs associated with chloroplasts or mitochondria, which may imply that functions of VvmTERF proteins are related to these organelles.

\section{Synteny analysis of VvmTERF and AtmTERF genes}

Arabidopsis is a well-studied model species which can provide available genomic information to a less-studied 


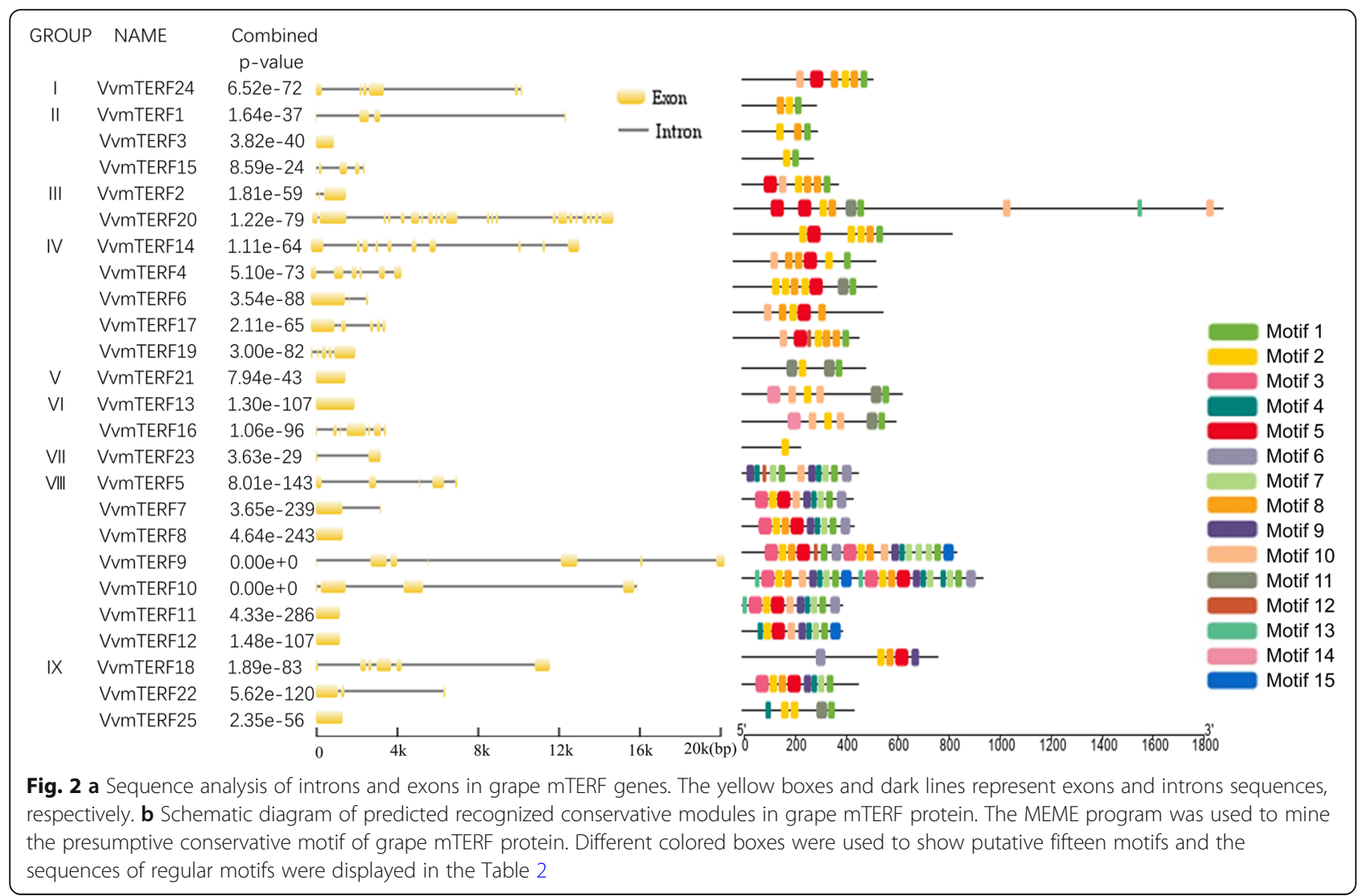

species through genomic comparison method [33, 34]. As showed in Fig. 3, a large-scale syntenies study containing 6 pairs of grape and Arabidopsis mTERF genes were recognized. Grape orthologues including VvmTERF2, VvmTERF6, VvmTERF13, VvmTERF15,
VvmTERF24 and VvmTERF25 displayed synteny location with Arabidopsis mTERF genes AtmTERF6, AtmTERF4, AtmTERF19, AtmTERF10, AtmTERF9 and AtmTERF17, respectively (Table $\mathrm{S} 2$ ). The number of synteny results indicated that several mTERF genes might arise before

Table 2 Multiple Em for Motif Elucidation (MEME) protein motifs identified in grape mTERF proteins

\begin{tabular}{lll}
\hline Motif No. & Width & Sequence \\
\hline 1 & 27 & ELVRFPQYLSYSLEKRIKPRHSWKV \\
2 & 30 & KIVTKYPEJLGASVEKTLKPKLEYLKSLG \\
3 & 51 & HSFTVSYLMNSCGLSPETAISASKKIQFENPENPDSVLALLRNHGCTDTH \\
4 & 24 & ESTWZQKMEVYRRWGFSEDEI \\
5 & 51 & SDSDVAKIJKKRPRILKYDLEKNJKPNIEFLKEJGIPDSSIAKVIARYPR \\
6 & 38 & AFLKLTEKKFLDRFVIKYZEDVPQLLNLYKGEVGIQE \\
7 & 26 & AFRKSPLCMQLSEKKIMSTMDFLVN \\
8 & 30 & DIARILSKYPQILGRSJENNLKPSVNYLV \\
9 & 30 & ENVKKVMEMGFBPLKLTFVYAJQVISQMS \\
10 & 31 & EENJLPNJAYLEEJGVPRSQISKLLTRYP \\
11 & 42 & KYGLSEEEVSEMFKKAPQVLQYSEDKIEEKIDYLVNKMGYP \\
12 & 16 & CMSLSEKKIMSTMDF \\
13 & 21 & MTQLHFLGNITPFVIRCF \\
14 & 51 & HCTRSFGFDAENMSKNSPFFLZKJLGKVENEQEIGKSJSKFLRYNPINE \\
15 & 41 & KKDLKLGHFLNLPEGDFLDKYVIKNQDEIPQLLDLYQGKV \\
\hline
\end{tabular}


Table 3 Subcellular localization of VvmTERF proteins

\begin{tabular}{|c|c|c|c|c|c|}
\hline \multirow{2}{*}{$\begin{array}{l}\text { Protein } \\
\text { name }\end{array}$} & \multicolumn{5}{|c|}{ Prediction scores } \\
\hline & Chloroplast & Mitochondrial & Cytoplasmic & Nuclear & Plasma Membrane \\
\hline VvmTERF1 & 0.144 & $2.201^{a}$ & 0.211 & $1.870^{a}$ & 0.041 \\
\hline VvmTERF2 & 0.230 & $1.288^{a}$ & $1.451^{\mathrm{a}}$ & $1.437^{\mathrm{a}}$ & 0.280 \\
\hline VvmTERF3 & 0.081 & $1.936^{\mathrm{a}}$ & 0.162 & $1.297^{\mathrm{a}}$ & 0.393 \\
\hline VvmTERF4 & 0.633 & 0.447 & 1.125 & 0.523 & $2.135^{a}$ \\
\hline VvmTERF5 & 0.317 & 0.915 & 1.094 & 0.246 & $1.968^{\mathrm{a}}$ \\
\hline VvmTERF6 & $1.286^{\mathrm{a}}$ & 0.786 & $1.684^{\mathrm{a}}$ & 0.567 & 0.322 \\
\hline VvmTERF7 & 0.353 & 1.111 & 0.177 & 0.228 & $2.402^{\mathrm{a}}$ \\
\hline VvmTERF8 & 0.821 & $1.264^{\mathrm{a}}$ & 0.105 & 0.445 & $1.939^{\mathrm{a}}$ \\
\hline VvmTERF9 & 0.333 & 0.909 & 0.563 & $1.033^{\mathrm{a}}$ & $1.551^{\mathrm{a}}$ \\
\hline VvmTERF10 & 0.241 & 0.789 & 0.313 & 0.425 & $2.649^{a}$ \\
\hline VvmTERF11 & 0.436 & 1.159 & 0.132 & 0.247 & $2.339^{\mathrm{a}}$ \\
\hline VvmTERF12 & 0.441 & $1.388^{\mathrm{a}}$ & 0.296 & 0.660 & $1.427^{\mathrm{a}}$ \\
\hline VvmTERF13 & 0.499 & $1.393^{\mathrm{a}}$ & $1.068^{\mathrm{a}}$ & 0.487 & $1.193^{\mathrm{a}}$ \\
\hline VvmTERF14 & 0.235 & 0.738 & 0.637 & $2.016^{a}$ & 1.048 \\
\hline VvmTERF15 & 0.127 & $1.210^{a}$ & 0.404 & $1.767^{\mathrm{a}}$ & 0.250 \\
\hline VvmTERF16 & 0.242 & 0.418 & 0.343 & 0.189 & $3.042^{\mathrm{a}}$ \\
\hline VvmTERF17 & 0.071 & 0.194 & 0.279 & 0.131 & $4.004^{\mathrm{a}}$ \\
\hline VvmTERF18 & 0.096 & 0.920 & 0.607 & $1.628^{a}$ & 0.943 \\
\hline VvmTERF19 & $1.663^{a}$ & $1.209^{a}$ & $1.057^{\mathrm{a}}$ & 0.332 & 0.301 \\
\hline VvmTERF20 & 0.696 & 0.283 & 0.301 & 0.950 & $2.268^{a}$ \\
\hline VvmTERF21 & 0.497 & $1.564^{a}$ & $1.782^{\mathrm{a}}$ & 0.556 & 0.271 \\
\hline VvmTERF22 & 0.113 & $3.074^{a}$ & 0.149 & 0.963 & 0.455 \\
\hline VvmTERF23 & 0.406 & 0.226 & 0.891 & 0.612 & 0.000 \\
\hline VvmTERF24 & 0.045 & 0.342 & 0.125 & $3.855^{\mathrm{a}}$ & 0.452 \\
\hline VvmTERF25 & 0.684 & $2.162^{a}$ & 0.205 & 0.181 & $1.546^{\mathrm{a}}$ \\
\hline
\end{tabular}

The subcellular localization is predicted based on the prediction scores for chloroplast, mitochondria, cytoplasmic, nuclear and plasma membrane location and numbers show the strength of prediction, with large value indicating strong prection

${ }^{a}$ indicating strong reliability of location

the divergence of Arabidopsis and grape lineages, and also suggested that partial deletion of the grape genes might occur in specific syntenic locations during genome evolution.

\section{Cis-element analysis of grape $m$ TERF gene promoters}

To understand the possible regulatory mechanism of VVmTERF genes in multiple stress responses and functions in chloroplast and mitochondrion, a 2-kb sequence upstream of the precited transcription start site (TSS) of each VvmTERF gene was analyzed by the PlantCARE database. Meanwhile, Actin1 was chosen in grape genome as the housekeeping gene (Fig. 4). The sequences of $V v m T E R F$ gene promoters were found to contain various hormone regulation-related cis-elements such as those responsive to auxin, MeJA (Methyl Jasmonate), gibberellin, abscisic acid and salicylic acid. In addition, various defense and stress-related elements were also observed. These elements included light and wound responsive elements, osmotic stress-related elements, and low temperature and drought responsive elements.

\section{Analysis of expression profiles among the grape mTERF genes in different tissues and organs}

To discover the potential function of VvmTERF proteins during different stages of grape development, the tissue/ organ-specific gene expression profiles of VVmTERF were analyzed in the $V$. vinifera $\mathrm{cv}$. Corvina global gene expression atlas from the GEO DataSet (GSE36128). This dataset contained expression information of 54 sample tissues and organs in different developmental stages acquired by microarray database (Fig. 5). The results showed that some VvmTERF genes such as VvmTERF6, 9, 11 and 23 displayed similar expression patterns in different tissues and organs, while other VvmTERF genes like VvmTERF1, 3, 10 and 16 


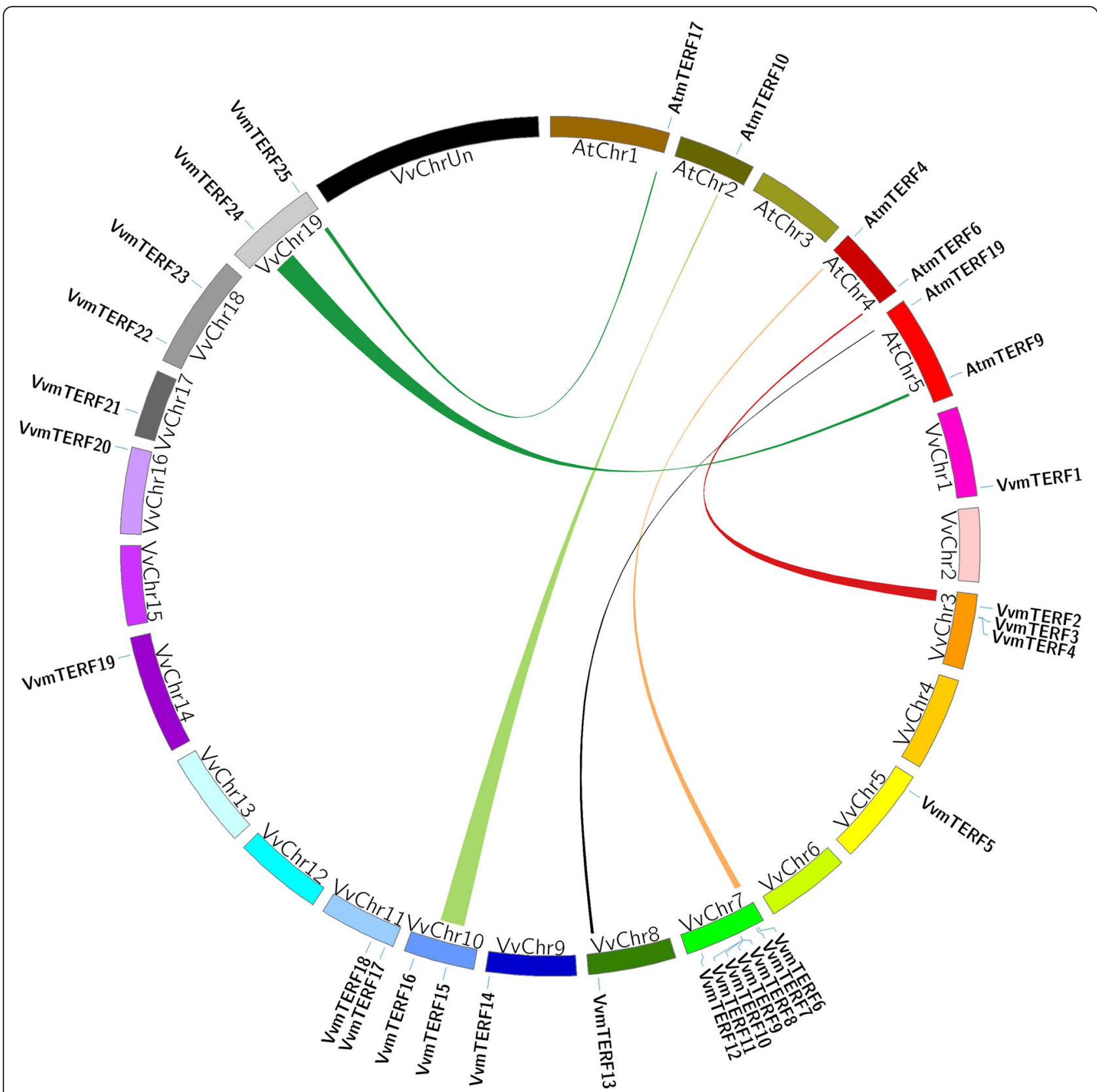

Fig. 3 Localization, duplication and synteny analysis of grape mTERF genes. Chromosomes 1-19 are marked using different colors and labeled with their names in a circular form. Syntenic regions are demonstrated by coloured curves between grape and Arabidopsis mTERF genes. Sequence contigs which cannot be located on corresponding chromosomes (1-19) will be assembled on "ChrUn"

demonstrated tissue/organ-specific expression patterns, suggesting multiple roles played by these VvmTERF genes family in grapevine.

\section{Expression patterns of VvmTERF genes under different exogenous hormone treatments}

To explore potential stress-related genes characterized in this research, plant signaling and regulatory hormones including, ABA, MeJA, SA and Eth were used for exogenous treatment [35]. Interestingly, almost all these
$V v m T E R F$ gene expressions were influenced by exogenous hormone treatments (Fig. 6 and Figure S2). For instance, after the ABA treatment, a total of 13 VvmTERF genes displayed multiple degrees of up regulation while 8 genes were down regulated. MeJA treatment led to the expression increase of $17 \mathrm{VvmTERF}$ genes and decrease on 7 genes. However, the expression patterns under SA and Eth treatments were different from those regulated by $\mathrm{ABA}$ and MeJA as more down regulated genes were observed. A total of $5 \quad V v$ mTERF genes were up 

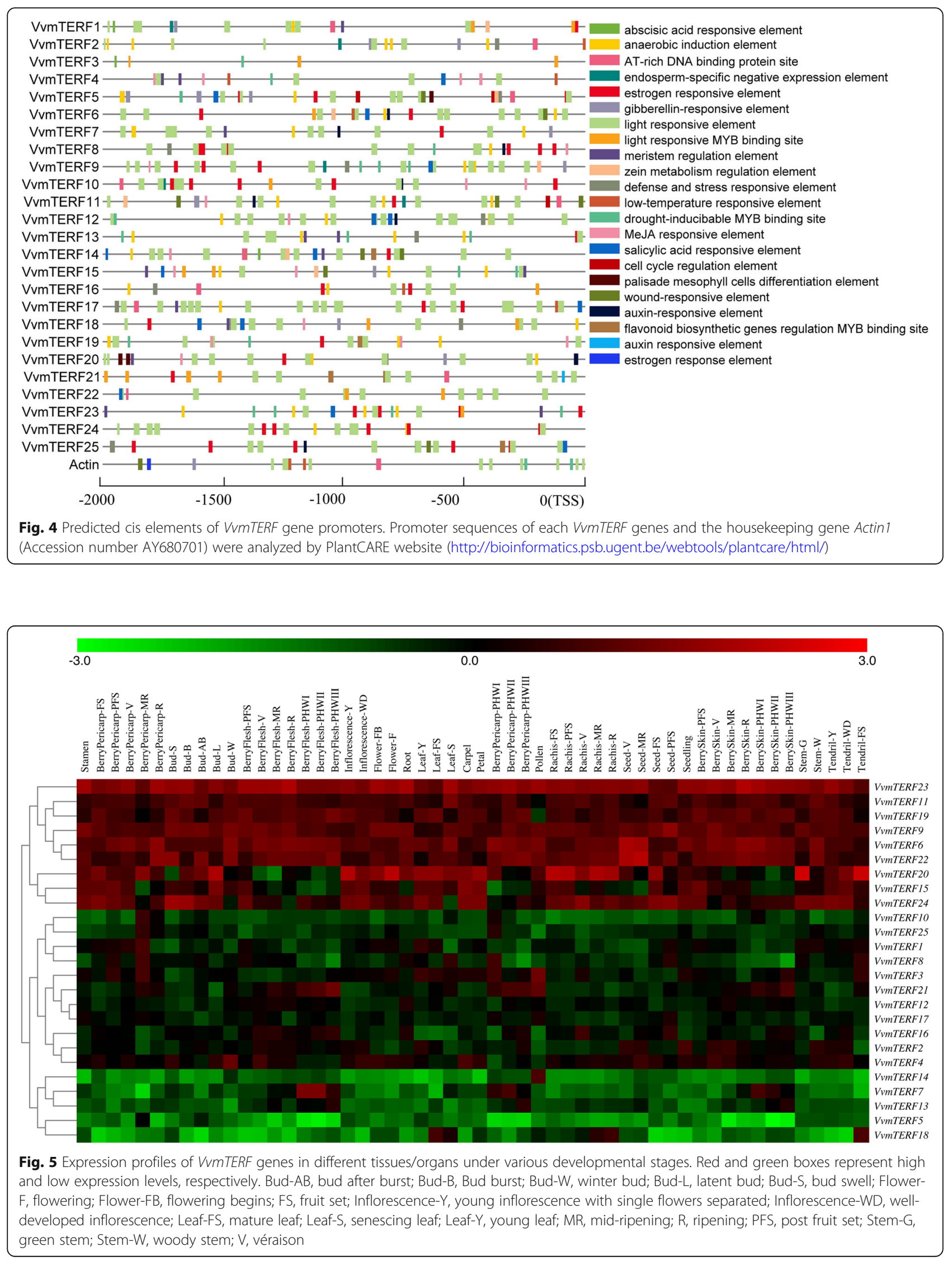


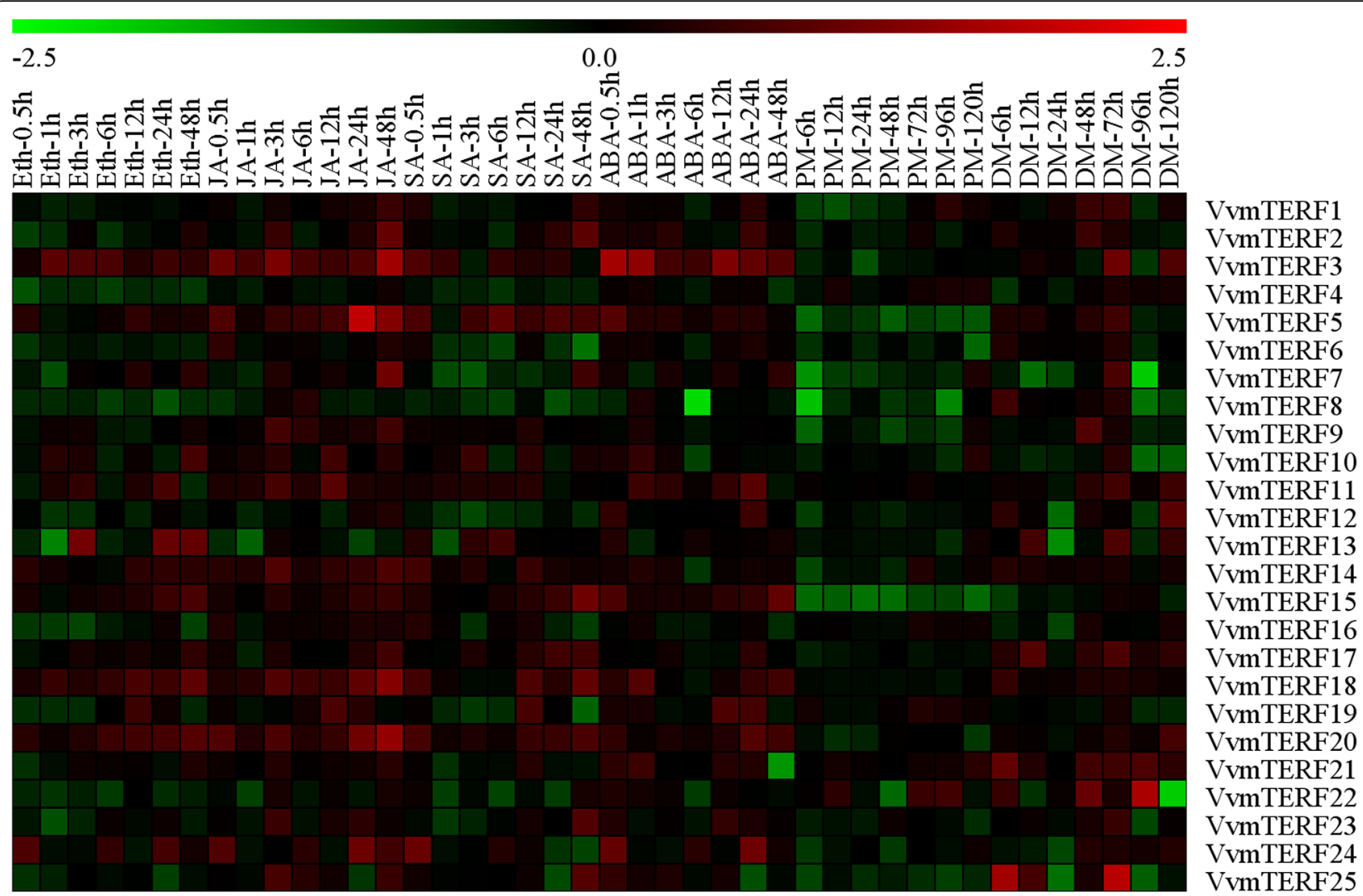

Fig. 6 Expression patterns of 25 mTERF genes in grape under treatments of phytohormones and biotic stresses. The Gene Tools software was used to quantify the brightness of semi-quantitative RT-PCR bands. MeV software was used for hierarchical cluster analysis to compare the grape mTERE genes under different hormone treatment and stresses. Red/green were used to indicate increased or decreased expression levels, respectively

regulated and 12 were down regulated by SA, while 7 were up regulated and 14 were down regulated by exogenous Eth hormone treatment. According to the semi-quantitative RT-PCR result, VvmTERF2, VvmTERF6, VvmTERF16, VvmTERF22 and $V v m T E R F 23$, which were downregulated by the Eth treatment, displayed significant upregulation under MeJA treatment, indicating an existence of different regulatory networks among these phytohormones. Meanwhile, the existence number of responsive ciselements of the promoter region may also play a role in the gene expression regulation.

\section{Expression profiles of $V_{v m T E R F}$ genes in response to biotic infections}

In order to adapt to changing environments, the ability to tolerate diverse array of stresses is an essential evolutionary trait in plant kingdom. Identification and functional analysis of genes involved in biological signal transduction pathways is of great significance in providing a fundamental information for plant development and stress responses. To investigate their role in responding to biotic stress, express analysis of the 25 VVITERF genes were conducted in potted 'Thompson Seedless' grapevines in greenhouse after inoculating with powdery mildew (PM) and downy mildew (DM) pathogens. As shown in Fig. 6, most VvmTERF genes demonstrated a tendency of downward expression after the inoculation. For instance, the expression of clade VII genes-VvmTERF5, 7-12-decreased in both E. necator and $P$. viticola treatments, while VvmTERF7 and VvmTERF10 genes have slightly decreased after $P$. viticola inoculation (Fig. 6, Fig. S3 and S4). Besides, the expression level of VvmTERF6, VvmTERF14 and VVmTERF19 held steady under both biotic treatments. On the other hand, VvmTERF11, VvmTERF17 and VvmTERF21 displayed an increasing trend in both PM and DM treatments in comparison with the control. Based on semi quantitative RT-PCR analysis, three grape mTERF genes (VvmTERF2, VvmTERF4 and VVITERF20) were chosen for further detailed analysis using real-time qPCR (Figs. 7 and 8). The qPCR results were consistent with the those obtained by semi quantitative RT-PCR. 


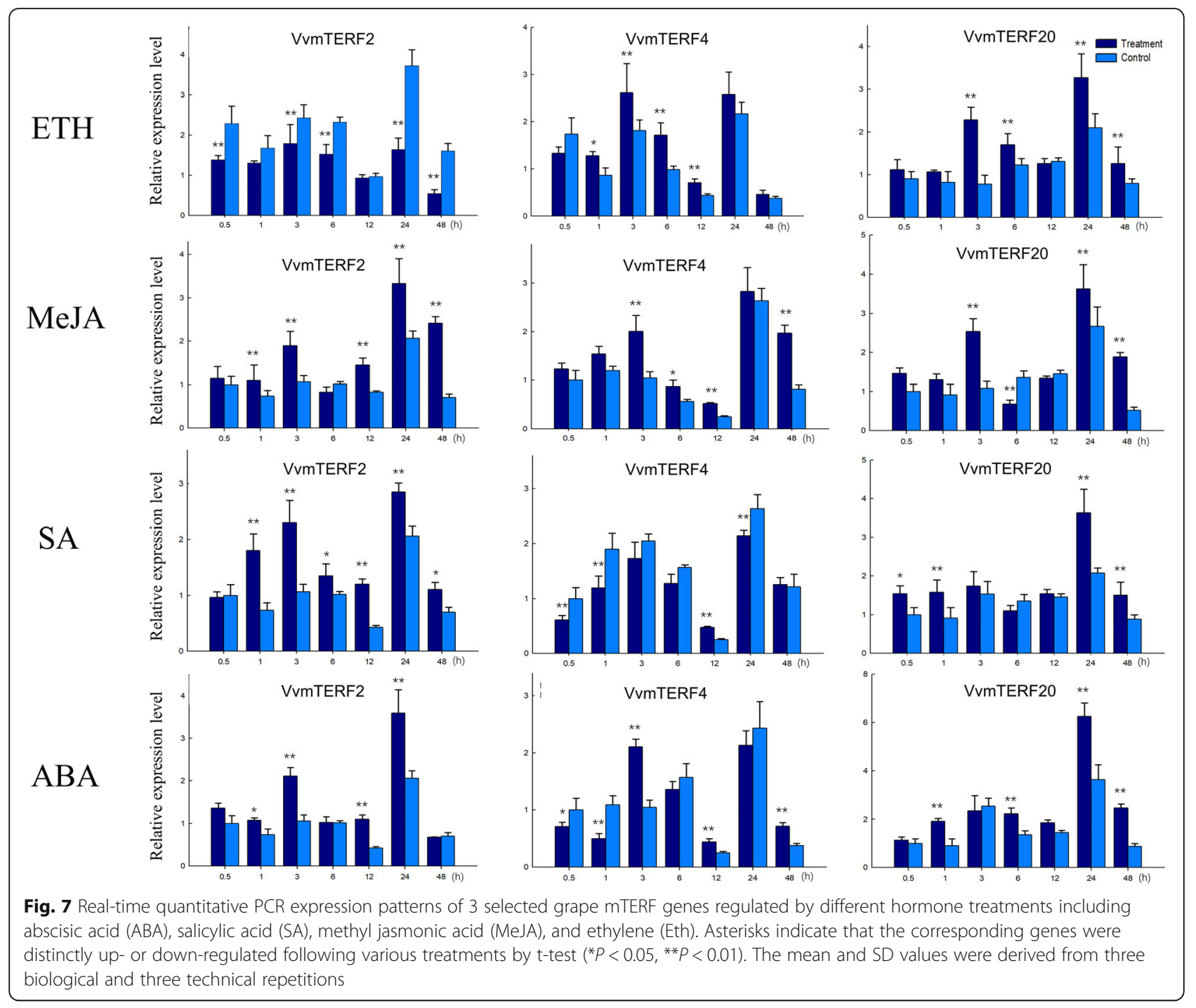

\section{Discussions}

Widely identified in metazoans and plants, mitochondrial transcription termination factors (mTERFs) can regulate the expression of organelle genes at different levels [36, 37]. Previous research showed that mTERF plays a significant regulatory role in the evolution of mitochondrial genes, leading to a fundamental role in mitochondrial functionality, biological evolution, gene diagnosis and treatment [38]. In plants, the expression of mitochondrial genes are fundamental for various plant biological functions [39]. To fully explore the functions of grape mTERF genes, it is essential to identify and characterize MTERF genes in grape genome. In the current study, 25 grape mTERF genes were identified and their structures, evolutionary traits and expression patterns in responding to biotic stresses and hormone treatments were also analyzed.

\section{Identification, annotation and evolution of VvmTERF} genes

In this study we investigated mTERF genes in grapevine and found 25 genes belonging to mTERF family that can be mapped onto the sequenced grape genome. The number of grape mTERF genes was less than that of Arabidopsis, despite the fact that grape has a much larger genome which would suggest the un-sequenced genomic gaps or mis-annotated genes of grape genome.

According to phylogenetic analysis, mTERF genes of Arabidopsis have been classified into eight groups [19]. In this study, a constructed phylogenetic tree which gathered the mTERF proteins from Arabidopsis, maize and grape had close topological framework to the tree constructed. Based on phylogenetic classification, grape mTERF genes were classified into nine groups. The number of clades I and VII of VvmTERF genes are small 


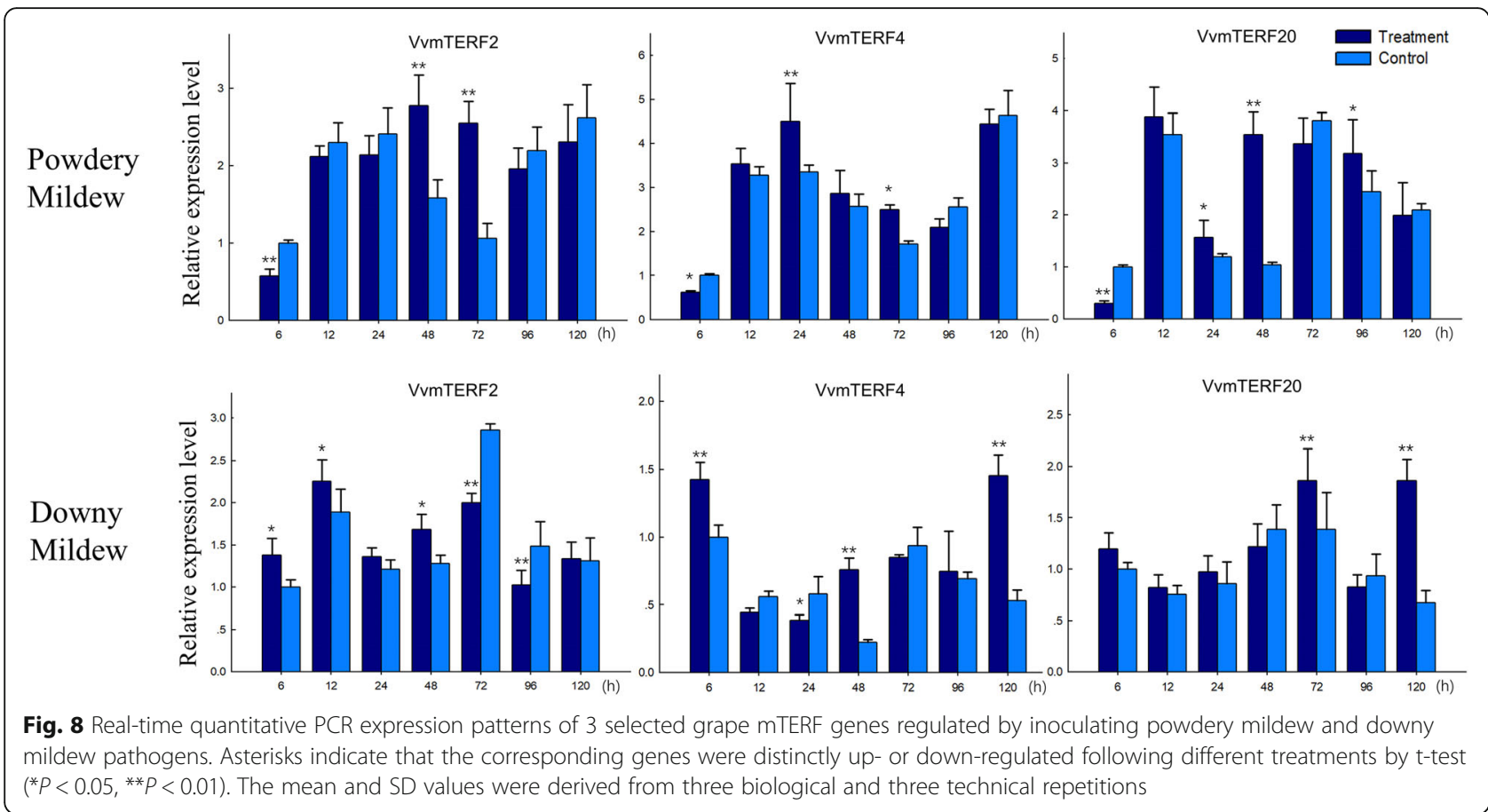

that could be due to a different pattern of duplication events. Furthermore, most of the VvmTERF genes were closely related to AtmTERF genes, which is in accordance with the fact that both grape and Arabidopsis are eudicots and exiting an appearance of close evolutional distance. As a result of highly conserved features, those mTERF genes which contain the same subclass may display similar functions. Multiple Arabidopsis mTERF genes functions have been tested, for instance, AtmTERF5, 9, 10 and 11 have functions on the resistance to salt and osmotic stress, and AtmTERF5, 9 and 10 also play roles in responding to ABA regulation [40]. Although the Arabidopsis mTERF genes can provide predicted characterization for VvmTERF genes, the functional analysis of VvmTERF genes homologs still need more detailed experimental demonstration.

\section{Expansion and synteny analysis of VvmTERF gene family}

During evolution, tandem, segmental and whole genome duplications have been commonly found in many organisms [34, 41]. In our study, based on the chromosome locations, motifs and sequences, we concluded that some of the VvmTERF genes such as VVmTERF3-4 and VVITERF8-11 might arise by tandem duplications. This leads to rearrangement and extension of the mTERF gene family, reported in other plant species [20, 28, 42], such as Arabidopsis genome [43]. Some of the Arabidopsis mTERF genes were considered to be generated by tandem duplications and one block duplication [19, 20]. On the other hand, it has been demonstrated that grape has gone through whole-genome duplication events distinctly [44]. Therefore, tandem and segmental duplications could probably contribute for most gene extensions, although there are different opinions on the exact nature and timing of these events [44, 45]. Similarly, tandem and segmental duplications have probably played a key role for grape mTERF gene expansions and their structural and functional diversity. Therefore, according to the comparison with respective orthologs of the model plant Arabidopsis, the putative functions of grape mTERF genes can be speculated. The current work analyzed the tandem duplication events of the 25 grape mTERF genes on the 13 grape chromosomes based on the research techniques of Holub [46], within $200 \mathrm{~kb}$ length on all chromosomes containing more than two genes that will be deemed to regard as a tandem duplication event.

In order to research a less-studied species, we often use genomic comparison method which could effectively transfer genomic knowledge obtained from a wellstudied model species (e.g. Arabidopsis) to a less studied organism [33, 47]. In this research, as seen in Fig. 3, synteny analysis of the grape and Arabidopsis genomes identified six pairs of mTERF genes (VvmTERF2-AtmTERF6, VvmTERF6-AtmTERF4, VvmTERF13-AtmTERF19, VvmTERF15-AtmTERF10, VvmTERF24AtmTERF9 and VvmTERF25-AtmTERF17) located in syntenic genomic regions (Fig. 3). Accompanied by selected genes loss, Arabidopsis and grape genomes have also gone through multiple and crucial chromosomal rearrangements and fusion processes during their evolution, which results in introduction of genes mismatches 
on chromosomes. In this case, we can deduce that the mTERF genes of grape and Arabidopsis in the same linear region may have a common ancestor. The first identified mTERF gene in Arabidopsis is AtmTERF1 (SOLDAT10), which is mainly involved in fluorescent phenotype and $\mathrm{O}^{2-}$ signaling cell death [21]. Furthermore, the AtmTERF4 (BSM/RUG2) gene is crucial for plant development. The rug2-1 and bsm mutant are unable to grow compared with the wild type plant. Sequence analysis revealed that VvmTERF6 was homologous to AtmTERF4 which might imply that the VVmTERF6 may have similar function in regulating plant development.

\section{VVmTERF genes response to hormone treatments and biotic stresses}

In a previous study, Linder [10] firstly described the mTERF gene family in plants leading to number of studies on identification of this family in various plant species. Identification and functional analysis of mTERF gene family in maize and pepper are among the best examples [28, 42]. However, information about mTERF functions in plants is still rather limited and needs further investigations. In this report, we analyzed the expression patterns of $V v m T E R F$ after exposing to various biotic and abiotic stresses including pathogens and phytohormones. Under these different treatments, the VVITERF genes showed various expression patterns, implying their crucial role in plant growth and response to environmental stresses.

Among the phytohormones, it has been reported that $\mathrm{ABA}$ is widely involved in various biological function in response to biotic and abiotic stress [48-50], while plant hormone Eth, SA and MeJA have synergistic effects on biological stress signals after pathogen infection [51]. Our results revealed that the grape mTERF genes responded to different plant hormones, which were consistent with former studies in other species such as maize and capsicum mTERF genes [28, 42].

A total of 35 mTERF genes were identified in A. thaliana, among which 6 mTERF genes were discovered specifically functional. Gene SOLDAT10 and SHOT1 for instance can respond to abiotic stresses [21, 52], as well as gene TWIRT1 has meristem function [53] and gene RUG2 is associated with leaf morphology [54]. VVITERF6 is a homolog of AtmTERF4 that has functions of organelles development and photoautotrophic growth. In Fig. 5, expression alteration of VvmTERF6 gene in the development stages of grape showed distinct upregulated pattern, indicating potential function during growth periods. It is interesting to note that 11 light responsive cis-elements were found from the promoter region of VvmTERF6 gene in Fig. 4, suggesting a role in grape growth and development. Named MDA1,
AtmTERF5 played a role in rooting process of model plant Arabidopsis and showed responses to abiotic treatment. On account of reducing sensitivity to hormone abscisic acid, mutant mda1 seedlings are exhibited insensitiveness to osmotic and salt stresses, while grown Arabidopsis $m d a 1$ plants demonstrate reduced tolerance to cold, salinity or ABA treatment [22]. Hence, since this gene family has expanded in plants, scientists found that this family is a suitable candidate for many mutantgenerating strategies in order to determine potent phenotypic, or even showed embryo-lethal feature. In addition to the results acquired from the mutant analysis, previously published mTERF genes expression data which had also clearly showed the potential role for mTERFs in plant stress response. In the report, ZmmTERF12 and ZmmTERF28 were down- and upregulated by ABA hormone treatment, respectively [28]. From the same clade with ZmmTERF28, VvmTERF25 also displayed quick response to ABA after $0.5 \mathrm{~h}$ treatment. It was found that abscisic acid responsive element appeared in the promoter region of VvmTERF25, implying the reason that $A B A$ lead to a positive regulation of $V v m T E R F 25$. Taken together, we analyzed the response of $V v m T E R F$ genes to various plant hormones and found potential key targets for enhancing grape stress resistance, which provided basic information for future studies on function of VvmTERF genes and its related signal transduction network.

Previous research demonstrated that some of the plant mTERF genes such as SOLDAT10 and SHOT1 participate in ROS scavenging process [52]. Given this, the role of mTERF genes in response to biotic stresses needs more information. Further we conducted the related experiment here and the results confirmed our hypothesis before. In this study, we found that some grape mTERF genes responded to powdery or downy mildew treatments. For example, VvmTERF22 was up regulated by $\mathrm{PM}$ at $12 \mathrm{~h}$, and $V v m T E R F 21$ positively responded to downy mildew infection. We detected several VvmTERF genes expression levels which are actively responsive to PM or DM treatments, indicating these genes might display significant characters in the grape protection, but further research is needful to demonstrate that they participate in biotic stress responses in grapevine.

\section{Conclusions}

The family of transcriptional activators encoded by the mTERF genes is widely found in plants and animals. Although significant progresses have been made in identifying mTERF genes in model plant species, little information of mTERF genes has been known in fruit crops. In this study, we identified a total of 25 VvmTERF genes in the grape genome, and also investigated their structural, phylogenetical and syntenic features. Through 
comparative analysis of homology between grape and Arabidopsis, it is found that several mTERF genes of grape and Arabidopsis are located in the homologous regions, indicating that they may present close evolutionary relationship. Expression analysis of VvmTERF genes showed that multiple genes could respond to different biological stresses and hormone treatments. Results from this study have paved the way for future research to investigate roles of VvmTERF genes on disease resistance of grapevines.

\section{Methods}

Identification and annotation of grape mTERF genes Conserved mTERF domains were first used to detect grape genes in mTERF HMM (Hidden Markov Model) file (PF02536) from the Pfam database [29] using the HMMER 3.0 package [26]. The domains were further used as the query to search the GenBank nonredundant protein and the Grape Genome Database (http://www. rosaceae.org/projects/grape_genome) using the BLAST program. All mTERF proteins with an $\mathrm{E}$ value $<0.01$ were collected and the domains were manually checked in each candidate VvmTERF gene.

\section{Multiple sequence alignment, phylogenetic analysis and classification}

A total of 25 VvmTERF genes containing mTERF core domains were identified. The CLUSTALX software was then used for multiple sequence alignment analysis including grape mTERF genes and those from Arabidopsis (AtmTERF) and maize (ZmmTERF) [32]. Based on the neighbor-joining method and maximum likelihood method for 1000 bootstrap replicates, a phylogenetic tree was constructed using MEGA5.0 software [55]. The $V v m T E R F$ genes were classified into clades ground on multiple sequence alignments with those AtmTERF and ZmMTERF genes.

\section{MEME motifs, conserved sequences and subcellular localization analysis of grape mTERF proteins}

The identification of known conserved motifs in grape mTERF proteins was conducted by BLAST against the SMART [30] and Pfam [29] database searching. The potential motifs in the putative mTERF family gene sequences were predicted by Multiple Em for Motif Elicitation (MEME) software [31] with the parameters as follow: the optimum width of every single motif distributed between 6 to 50, and the maximum number of motifs to find was 15 . After that, the collection and cluster of mTERF motifs from grape mTERF proteins were conducted using the ClustalW 2.0 program software [32], and graphical representation of amino acid residues was arranged by TBtools [56].
The presumptive subcellular localizations of VvmTERF proteins were predicted by VvmTERF protein sequences in the online program Cellov2.5 Server (http://cello.life.nctu.edu.tw/) [57].

\section{Exon-intron structure analysis, synteny analysis and gene duplication}

According to alignments of grape mTERF gene coding sequences and their respective full-length sequences, the exon-intron structure was determined on Grape Genome Browser: http://www.genoscope.cns.fr/externe/ GenomeBrowser/Vitis/. And the online program Gene Structure Display Server (GSDS: http://gsds.cbi.pku.edu. ch) [58] was carried out to obtain relative diagrams. Besides, the definition of mTERF genes with tandem duplication events were adjacent homologous genes on a single chromosome, while gene duplication events among diverse chromosomes were defined as segmental duplications [59]. The specific physical location of each VVITERF gene on its individual chromosome determines whether it is considered in a tandem duplication event. Therefore a synteny analysis map of grape mTERF gene was constructed via the syntenic blocks, and a further synteny analysis between grape and AtmTERF genes was acquired from the Plant Genome Duplication Database [60]. The generation of related diagrams were illustrated using Circos version website (http://circos.ca/).

\section{Cis-element analysis of grape mTERF genes promoter}

The 2000 bps upstream promoter sequence of each grape mTERF gene coding regions were obtained from the grape genome database (https://wwwdev.genoscope.cns.fr/vitis). PlantCARE online analysis program (http:// bioinformatics.psb.ugent.be/webtools/plantcare/html/) was used to find the predicted cis-element.

\section{Expression profiles of grape $m T E R F$ gene family in different tissues and organs}

The expression profile of grape mTERF gene family was confirmed in a $V$. vinifera cv 'Corvina' (clone48) gene expression atlas of various organs at different developmental stages. Microarray data were collected from the NCBI gene expression omnibus (GEO) datasets under the series entry GSE36128 (http://www.ncbi.nlm.nih.gov/geo/) [61]. The mean expression value of grape mTERF genes in all tissues and organs were analyzed and detailed displayed by Multiple Experiment Viewer software (MeV) [62] Measured using RNA-Seq data, the expression patterns of $V v m T E R F$ genes in various berry developmental stages were gained from gene expression omnibus (GEO) database of NCBI (GSE77218) [63]. 


\section{Plant materials and stress treatments}

To validate the expression regulation of grape mTERF genes under abiotic and biotic stresses, grape leaves and organs were obtained from $V$. vinifera 'Thompson Seedless' grape grown in a greenhouse. When the shoots of the grapevines reached $30 \mathrm{~cm}$ long with fully expanded young leaves, the plants were subjected to hormone treatment. Hormone treatment was carried out on grape leaves under similar growth condition, spraying with $100 \mu \mathrm{M}$ salicylic acid (SA), $300 \mu \mathrm{M}$ abscisic acid (ABA), $50 \mu \mathrm{M}$ methyl jasmonate (MeJA), and $0.5 \mathrm{~g} / \mathrm{l}$ ethylene (Eth), respectively [34]. Leaves from the treated vines were collected at $0.5,1,3,6,12,24$, and $48 \mathrm{~h}$ post treatment. Grape leaves sprayed with sterile water were used as the negative control.

In term of biotic stress, powdery mildew (Erysiphe necator) and downy mildew (Plasmopara viticola) pathogens were used to inoculate young leaves of $V$. vinifera 'Thompson Seedless' following previous protocol [64, 65]. Leaves were sampled at 6, 12, 24, 48, 72, 96, and $120 \mathrm{~h}$ post inoculation and untreated leaves were collected as the negative control. At each time point of all treatments, nine leaves from three separate plants were homogenized, and the treatments were conducted three times independently. These grape leaves were frozen in liquid nitrogen and stored at $-80^{\circ} \mathrm{C}$ for further use.

\section{Semiquantitative PCR and real-time quantitative PCR analysis}

The total RNA was extracted as described by Zhang et al. [47]. The genomic DNA was digested using RNase-free DNase I kit (OMEGA Bio Inc., USA). The grape Actin1 gene (GenBank Accession number AY680701) and EF1- $\alpha$ (GenBank Accession number EC931777) gene were chosen as housekeeping genes and amplified with the primers showing in Table S1, which also includes Gene-specific primers for the $25 \mathrm{VvmTERF}$ genes. For the semi-quantitative reverse transcriptionPCR experiment, the volume of reaction system was $20 \mu \mathrm{L}$ which includes $1 \mu \mathrm{L} \mathrm{cDNA}$ template, $1 \mu \mathrm{L}$ forward and reverse gene-specific primers $(10 \mu \mathrm{M}), 10 \mu \mathrm{L}$ PCR Master Mix (Qingke Biotech Co. Ltd., Shanghai, China) and $8 \mu \mathrm{L}$ sterile water, the specific proportion and program were set according to the PCR Master Mix instruction book. Each PCR reaction was conducted in duplicate. The Gene Tools software was used for quality control of semi-quantitative PCR results, further logtransformed values of the relative expression patterns of $V V m T E R F$ genes under various phytohormone and biotic stresses treatment were used to perform hierarchical cluster using Mev software [62].

Quantitative real-time PCR analysis was performed with an IQ5 real-time PCR instrument (Bio-Rad, Hercules, CA, USA). All reactions were performed in triplicate with a reaction system of $20 \mu \mathrm{L}$ including $1 \mu \mathrm{L}$ specific primers $(10 \mu \mathrm{M}), 1 \mu \mathrm{L}$ cDNA, $10 \mu \mathrm{L}$ SYBR green (Yeasen Biotech Co Ltd., Shanghai, China), and $8 \mu \mathrm{L}$ sterile water, the specific proportion was on the instruction book as well as the PCR parameters. The grape Actin1 gene (GenBank Accession number AY680701) was chosen as the housekeeping gene. The expression levels of grape mTERF genes were analyzed using IQ5 software with the normalized expression method. The ttest was conducted using the SPSS software (SPSS 17.0, Chicago, IL, USA, $\left.{ }^{*} P<0.05,{ }^{* *} P<0.01\right)$.

\section{Supplementary Information}

The online version contains supplementary material available at https://doi. org/10.1186/s12864-021-07446-z.

Additional file 1: Figure S1. Phylogenetic analysis among the grape Arabidopsis and maize mTERF proteins. The unrooted tree was constructed using MEGA5.0 software by Maximum Likelihood method for 1000 bootstrap replicates. Three dot colors mean different species. Yellow, green and red represent maize, Arabidopsis and grape, respectively.

Additional file 2: Figure S2. Expression patterns of 25 VVmTERF genes under hormone Eth, MeJA, SA and ABA treatments analyzed by semiquantitative RT-PCR. Actin 1 and EF-1a (GenBank Accession number AY680701 and EC931777) were used as internal reference genes. The upper and lower bands indicate treatment and control, respectively.

Additional file 3: Figure S3. Expression patterns of 25 V VmTERF genes after inoculation of downy mildew and powdery mildew treatments analyzed by semi-quantitative RT-PCR. Actin1 and EF-1a (GenBank Accession number AY680701 and EC931777) were used as internal reference genes. The upper and lower bands indicate treatment and control, respectively.

Additional file 4: Figure S4. Expression profiles of 25 V VmTERF genes under exogenous hormone and biotic treatments. Numbers in boxes represent different expression levels. 0 indicates no change, number less than zero means down-regulated expression and more than zero means up-regulated expression

Additional file 5: Table S1. Primer sequences used for semiquantitative RT-PCR and quantitative real-time PCR of the 25 grape mTERF genes. Primer 5.0 software were used to designed specific primers.

Additional file 6: Table S2. Synteny blocks of VVmTERF genes between the grape and Arabidopsis genomes.

\section{Abbreviations}

mTERFs: Mitochondrial transcription termination factor; VvmTERFs: Vitis vinifera mitochondrial transcription termination factor;

PPRs: Pentatricopeptide repeat proteins; HAT: Half atetratricopeptide proteins; OPR: Octotricopeptide repeat proteins; rRNA: Ribosomal RNA; Eth: Ethylene; SA: Salicylic acid; MeJA: Methyl Jasmonate; ABA: Abscisic acid; RTqPCR: Reverse transcription quantitative PCR

\section{Acknowledgements}

The authors thank all editors and reviewers for their comments on this manuscript.

\section{Authors' contributions}

$J \mathrm{~L}$ and $X Y$ : conceived and designed the experiments. $X Y, S S$ and $Y G$ : performed the experiments, contributed reagents/materials/analysis tools and analyzed the data; XY, DH and JL wrote the manuscript. YG: provided guidance for the entire study. All authors approved the final manuscript. 


\section{Funding}

This work was supported by Shanghai Agriculture Applied Technology Development Program (Grant No. 2018-02-08-00-08-F01552); National Key R \& D Program of China (2018 YFD100300); the National Natural Science Foundation of China (No. 31801830 and 31701775); the Shanghai Jiao Tong University New Scholar Start-Up Fund (AF1500068); Shanghai Municipal Commission for Science and Technology (18391900400); China Agriculture Research System (CARS-29-yc-2).

\section{Availability of data and materials}

All data generated or analyzed during this study are included in this published article and its additional files.

\section{Ethics approval and consent to participate}

Not applicable.

\section{Consent for publication}

Not applicable.

\section{Competing interests}

The authors declare that they have no competing interests.

\section{Author details}

${ }^{1}$ Center for Viticulture and Enology, School of Agriculture and Biology, Shanghai Jiao Tong University, Shanghai 200240, China. ${ }^{2} J$ oint International Research Laboratory of Metabolic and Developmental Sciences, Key Laboratory of Urban Agriculture (South) Ministry of Agriculture, Plant Biotechnology Research Center, Fudan-SJTU-Nottingham Plant Biotechnology R\&D Center, School of Agriculture and Biology, Shanghai Jiao Tong University (SJTU), Shanghai 200240, China.

Received: 7 September 2020 Accepted: 15 February 2021 Published online: 26 February 2021

\section{References}

1. Kleine T, Voigt C, Leister D. Plastid signalling to the nucleus: messengers still lost in the mists? Trends Genet. 2009;25(4):185-90.

2. Martin W, Rujan T, Richly E, Hansen A, Cornelsen S, Lins T, Leister D, Stoebe B, Hasegawa M, Penny D. Evolutionary analysis of Arabidopsis, cyanobacterial, and chloroplast genomes reveals plastid phylogeny and thousands of cyanobacterial genes in the nucleus. P Natl Acad Sci USA. 2002;99(19):12246-51.

3. Timmis JN, Ayliffe MA, Huang CY, Martin W. Endosymbiotic gene transfer: organelle genomes forge eukaryotic chromosomes. Nat Rev Genet. 2004; 5(2):123-U116.

4. Hammani K, Barkan A. An mTERF domain protein functions in group II intron splicing in maize chloroplasts. Nucleic Acids Res. 2014;42(8):5033-42.

5. Barkan A. Studying the structure and processing of chloroplast transcripts. Methods Mol Biol. 2011;774:183-97.

6. Rackham O, Mercer TR, Filipovska A. The human mitochondrial transcriptome and the RNA-binding proteins that regulate its expression. Wiley Interdiscip Rev RNA. 2012;3(5):675-95.

7. Stoppel R, Meurer J. The cutting crew - ribonucleases are key players in the control of plastid gene expression. J Exp Bot. 2012;63(4):1663-73.

8. Yagi Y, Shiina T. Recent advances in the study of chloroplast gene expression and its evolution. Front Plant Sci. 2014;5:61.

9. Kleine T, Leister D. Emerging functions of mammalian and plant mTERFs. Biochim Biophys Acta. 2015;1847(9):786-97.

10. Linder T, Park CB, Asin-Cayuela J, Pellegrini M, Larsson NG, Falkenberg M, Samuelsson T, Gustafsson CM. A family of putative transcription termination factors shared amongst metazoans and plants. Curr Genet. 2005;48(4):265-9.

11. Roberti M, Bruni F, Polosa PL, Manzari C, Gadaleta MN, Cantatore P. MTERF3, the most conserved member of the mTERF-family, is a modular factor involved in mitochondrial protein synthesis. Bba-Bioenergetics. 2006;1757(910):1199-206.

12. Roberti M, Polosa PL, Bruni F, Manzari C, Deceglie S, Gadaleta MN, Cantatore $P$. The MTERF family proteins: mitochondrial transcription regulators and beyond. Bba-Bioenergetics. 2009;1787(5):303-11.

13. Kruse B, Narasimhan N, Attardi G. Termination of transcription in human mitochondria: identification and purification of a DNA binding protein factor that promotes termination. Cell. 1989;58(2):391-7.
14. FernandezSilva P, MartinezAzorin F, Micol V, Attardi G. The human mitochondrial transcription termination factor (mTERF) is a multizipper protein but binds to DNA as a monomer, with evidence pointing to intramolecular leucine zipper interactions. EMBO J. 1997;16(5):1066-79.

15. Martin M, Cho JY, Cesare AJ, Griffith JD, Attardi G. Termination factormediated DNA loop between termination and initiation sites drives mitochondrial rRNA synthesis. Cell. 2005;123(7):1227-40.

16. Wenz T, Luca C, Torraco A, Moraes CT. mTERF2 regulates oxidative phosphorylation by modulating mtDNA transcription. Cell Metab. 2009;9(6): 499-511.

17. Quesada V. The roles of mitochondrial transcription termination factors (MTERFs) in plants. Physiol Plantarum. 2016;157(3):389-99.

18. Robles P, Micol JL, Quesada V. Unveiling plant mTERF functions. Mol Plant. 2012;5(2):294-6.

19. Babiychuk E, Vandepoele K, Wissing J, Garcia-Diaz M, De Rycke R, Akbari H, Joubes J, Beeckman T, Jansch L, Frentzen M, et al. Plastid gene expression and plant development require a plastidic protein of the mitochondrial transcription termination factor family. P Natl Acad Sci USA. 2011;108(16): 6674-9.

20. Kleine T. Arabidopsis thaliana mTERF proteins: evolution and functional classification. Front Plant Sci. 2012;3:233.

21. Meskauskiene R, Wursch M, Laloi C, Vidi PA, Coll NS, Kessler F, Baruah A, Kim C, Apel K. A mutation in the Arabidopsis mTERF-related plastid protein SOLDAT10 activates retrograde signaling and suppresses 10(2)-induced cell death. Plant J. 2009;60(3):399-410.

22. Robles P, Micol JL, Quesada V. Arabidopsis MDA1, a nuclear-encoded protein, functions in chloroplast development and abiotic stress responses. Plos One. 2012;7(8):e42924.

23. Robles P, Micol JL, Quesada V. Mutations in the plant-conserved MTERF9 alter chloroplast gene expression, development and tolerance to abiotic stress in Arabidopsis thaliana. Physiol Plantarum. 2015;154(2):297-313.

24. Kamel H. Alice BJNAR. An mTERF domain protein functions in group II intron splicing in maize chloroplasts. 2014;8:8.

25. Kreamer RJA. US table grape exports scoring big in world markets; 1995.

26. Eddy SR. Hidden Markov models. Curr Opin Struct Biol. 1996;6(3):361-5.

27. Inal B, Ilhan E, Büyük I, Altıntaş S. Transcriptome wide characterization of water deficit responsive grape mTERF transcription. J Plant Biochem Biot. 2020;29(1):102-13.

28. Zhao YX, Cai MJ, Zhang XB, Li YR, Zhang JH, Zhao HL, Kong F, Zheng YL, Qiu FZ. Genome-wide identification, evolution and expression analysis of mTERF gene family in Maize. Plos One. 2014;9(4):e94126.

29. Punta M, Coggill PC, Eberhardt RY, Mistry J, Tate J, Boursnell C, Pang N, Forslund K, Ceric G, Clements J, et al. The Pfam protein families database. Nucleic Acids Res. 2012;40(D1):D290-301.

30. Letunic I, Doerks T, Bork P. SMART 7: recent updates to the protein domain annotation resource. Nucleic Acids Res. 2012;40(D1):D302-5.

31. Bailey TL, Boden M, Buske FA, Frith M, Grant CE, Clementi L, Ren JY, Li WW, Noble WS. MEME SUITE: tools for motif discovery and searching. Nucleic Acids Res. 2009;37:W202-8.

32. Larkin MA, Blackshields G, Brown NP, Chenna R, McGettigan PA, McWilliam H, Valentin F, Wallace IM, Wilm A, Lopez R, et al. Clustal W and clustal X version 2.0. Bioinformatics. 2007;23(21):2947-8.

33. Lyons E, Pedersen B, Kane J, Alam M, Ming R, Tang HB, Wang XY, Bowers J, Paterson A, Lisch D, et al. Finding and comparing Syntenic regions among Arabidopsis and the Outgroups papaya, poplar, and grape: CoGe with Rosids. Plant Physiol. 2008;148(4):1772-81.

34. Guo CL, Guo RR, Xu XZ, Gao M, Li XQ, Song JY, Zheng Y, Wang XP. Evolution and expression analysis of the grape (Vitis vinifera L.) WRKY gene family. J Exp Bot. 2014;65(6):1513-28.

35. Fujita M, Fujita Y, Noutoshi Y, Takahashi F, Narusaka Y, Yamaguchi-Shinozaki K, KJCoipb S. Crosstalk between abiotic and biotic stress responses: a current view from the points of convergence in the stress signaling networks. Curr Opin Plant Biol. 2006;9(4):436-42.

36. Nedialkov YA, Opron K, Assaf F, Artsimovitch I, Kireeva ML, Kashlev M, Cukier RI, Nudler E, Burton ZF. The RNA polymerase bridge helix YFI motif in catalysis, fidelity and translocation. Bba-Gene Regul Mech. 2013;1829(2):187-98.

37. Leister D, Kleine T. Extending the repertoire of mTERF proteins with functions in Organellar gene expression. Mol Plant. 2020;13(6):817-9.

38. DiMaggio C, Markenson D, Loo GT, Redlener I. The willingness of US emergency medical technicians to respond to terrorist incidents. Biosecur Bioterror. 2005;3(4):331-7. 
39. Karaca M, Ince AG, Ay ST, Turgut K, Onus AN. PCR-RFLP and DAMD-PCR genotyping for Salvia species. J Sci Food Agr. 2010;88(14):2508-16.

40. Xu DR, Leister D, Kleine T. Arabidopsis thaliana mTERF10 and mTERF11, but Not mTERF12, are involved in the response to salt stress. Front Plant Sci. 2017:8:1213

41. Xu G, Guo C, Shan H, Kong H. Divergence of duplicate genes in exon-intron structure. Proc Natl Acad Sci U S A. 2012;109(4):1187-92.

42. Tang B, Xie L, Yi T, Lv J, Yang H, Cheng X, Liu F, Zou X. Genome-wide identification and characterization of the mitochondrial transcription termination factors (mTERFs) in Capsicum annuum L. Int J Mol Sci. 2019; 21(1):269.

43. Maere S, De Bodt S, Raes J, Casneuf T, Van Montagu M, Kuiper M, Van de Peer Y. Modeling gene and genome duplications in eukaryotes. Proc Natl Acad Sci U S A. 2005;102(15):5454-9.

44. Jaillon O, Aury JM, Noel B, Policriti A, Clepet C, Casagrande A, Choisne N, Aubourg S, Vitulo N, Jubin C, et al. The grapevine genome sequence suggests ancestral hexaploidization in major angiosperm phyla. Nature. 2007:449(7161):463-U465.

45. Velasco R, Zharkikh A, Troggio M, Cartwright DA, Cestaro A, Pruss D, Pindo M, Fitzgerald LM, Vezzulli S, Reid J, et al. A high quality draft consensus sequence of the genome of a heterozygous grapevine variety. PLoS One. 2007;2(12):e1326.

46. Holub EB. The arms race is ancient history in Arabidopsis, the wildflower. Nat Rev Genet. 2001;2(7):516-27.

47. Zhang YC, Mao LY, Wang H, Brocker C, Yin XJ, Vasiliou V, Fei ZJ, Wang XP. Genome-wide identification and Analysis of Grape Aldehyde Dehydrogenase (ALDH) Gene Superfamily. Plos One. 2012;7(2):e32153.

48. Mauch-Mani B, Mauch F. The role of abscisic acid in plant-pathogen interactions. Curr Opin Plant Biol. 2005;8(4):409-14.

49. Davies WJ, Jones HG. Abscisic acid physiology and biochemistry. Abscisic acid: physiology and biochemistry. Bios Sci. 1992;16(2):99.

50. Jameson PE, Murray BG. Abscisic acid physiology and biochemistry. New Zeal J Bot. 1992;30(3):369-71.

51. Glazebrook J. Contrasting mechanisms of defense against biotrophic and necrotrophic pathogens. Annu Rev Phytopathol. 2005;43:205-27.

52. Kim M, Lee U, Small I, Cc d F-S, Vierling E. Mutations in an Arabidopsis mitochondrial transcription termination factor-related protein enhance Thermotolerance in the absence of the major molecular chaperone HSP101. Plant Cell. 2012;24(8):3349-65.

53. Mokry M, Nijman IJ, van Dijken A, Benjamins R, Heidstra R, Scheres B, Cuppen E. Identification of factors required for meristem function in Arabidopsis using a novel next generation sequencing fast forward genetics approach. BMC Genomics. 2011;12.

54. Quesada V, Sarmiento-Manus R, Gonzalez-Bayon R, Hricova A, Perez-Marcos R, Gracia-Martinez E, Medina-Ruiz L, Leyva-Diaz E, Ponce MR, Micol JL. Arabidopsis RUGOSA2 encodes an mTERF family member required for mitochondrion, chloroplast and leaf development. Plant J. 2011;68(4):73853.

55. Tamura K, Peterson D, Peterson N, Stecher G, Nei M, SJMb K. Evolution. MEGA5: molecular evolutionary genetics analysis using maximum likelihood, evolutionary distance, and maximum parsimony methods. Mol Biol Evol. 2011;28(10):2731-9.

56. Chen $\mathrm{C}$, Chen $\mathrm{H}, \mathrm{He}$ Y, RJB X. TBtools, a toolkit for biologists integrating various biological data handling tools with a user-friendly interface, vol. 289660; 2018

57. Yu CS, Chen YC, Lu CH, Hwang JK. Prediction of protein subcellular localization. Proteins-Structure Function and Bioinformatics. 2006:64(3):64351.

58. Hu B, Jin JP, Guo AY, Zhang H, Luo JC, Gao G. GSDS 2.0: an upgraded gene feature visualization server. Bioinformatics. 2015;31(8):1296-7.

59. Liu Y, Jiang H, Chen W, Qian Y, Ma Q, Cheng B, Zhu SJPGR. Genome-wide analysis of the auxin response factor (ARF) gene family in maize (Zea mays) 2011; 63(3):225-234.

60. Tang H, Wang X, Bowers JE, Ming R, Alam M, AHJGr P. Unraveling ancient hexaploidy through multiply-aligned angiosperm gene maps. Genome Res. 2008;18(12):1944-54.

61. Fasoli M, Dal Santo S, Zenoni S, Tornielli GB, Farina L, Zamboni A, Porceddu A, Venturini L, Bicego M, Murino V, et al. The grapevine expression atlas reveals a deep Transcriptome shift driving the entire plant into a maturation program. Plant Cell. 2012;24(9):3489-505.
62. Saeed Al, Hagabati NK, Braisted JC, Liang W, Sharov V, Howe EA, Li JW, Thiagarajan M, White JA, Quackenbush J. TM4 microarray software suite. Method Enzymol. 2006;411:134

63. Shangguan $L, M u ~ Q$, Fang X, Zhang K, JJPO F. RNA-Sequencing Reveals Biological Networks during Table Grapevine ('Fujiminori') Fruit Development. PLoS One. 2017;12(1):e0170571.

64. Guan X, Zhao H, Xu Y, YJP W. Transient expression of glyoxal oxidase from the Chinese wild grape Vitis pseudoreticulata can suppress powdery mildew in a susceptible genotype. Protoplasma. 2011;248(2):415-23.

65. Li X, Wu J, Yin L, Zhang Y, Qu J, Lu JJPP. Biochemistry. Comparative transcriptome analysis reveals defense-related genes and pathways against downy mildew in Vitis amurensis grapevine, vol. 95; 2015. p. 1-14.

\section{Publisher's Note}

Springer Nature remains neutral with regard to jurisdictional claims in published maps and institutional affiliations.
Ready to submit your research? Choose BMC and benefit from:

- fast, convenient online submission

- thorough peer review by experienced researchers in your field

- rapid publication on acceptance

- support for research data, including large and complex data types

- gold Open Access which fosters wider collaboration and increased citations

- maximum visibility for your research: over $100 \mathrm{M}$ website views per year

At BMC, research is always in progress.

Learn more biomedcentral.com/submissions 